ISSN 2078-3744. Вісник Львів. ун-ту. Серіл мех.-мат. 2020. Випуск 89. С. 106-122

Visnyk of the Lviv Univ. Series Mech. Math. 2020. Issue 89. P. 106-122

http://publications.lnu.edu.ua/bulletins/index.php/mmf

doi: http://dx.doi.org/10.30970/vmm.2020.89.106-122

УДК 539.3, 539.4, 539.5

\title{
GENERALIZATION OF THE EQUIVALENT AREA METHOD FOR THE CASE OF SHORT FATIGUE CRACKS IN A THREE-DIMENSIONAL BODY
}

\author{
Nataliya YADZHAK \\ Ivan Franko National University of Lviv, \\ Universytetska Str., 1, 79000, Lviv, Ukraine \\ e-mail: nataliya.yadzhak@lnu.edu.ua
}

\begin{abstract}
In industry, structural elements with small cracks are widely used; however, little research has been done on relatively simple methods for lifetime evaluation of such structural elements. This study proposes a generalization of the equivalent area method for a case of small fatigue cracks using an alternative representation of the relation between the crack propagation rate and the crack tip opening. A tension problem for a three-dimensional body with an elliptical crack has been solved analytically by applying the generalized equivalent area method and numerically by the Runge-Kutta method. The comparison of the obtained solutions has shown a good correlation of the results that confirms the potential application of the generalized equivalent area method to short crack problems.

Key words: short cracks, fatigue fracture of three-dimensional bodies, elliptical crack, equivalent area method, opening of the fracture process zone
\end{abstract}

\section{INTRODUCTION}

For a simplified determination of residual lifetime of materials and structural elements, the equivalent area method can be applied, which helps to calculate lifetime for different problems, such as long cracks [1, p. 85-89], [2], elliptical edge cracks [1, p. 87$89]$ and creep cracks [3].

However, in structural elements under operation, mostly small cracks prevail, since structural elements with long cracks are subject to repair or replacement. Even though structural elements with short cracks are mostly under operation, the approximated investigation methods for such cases are relatively little developed. In this study, an attempt has been made to formulate such method for a case of small cracks; namely, to

2020 Mathematics Subject Classification: 74R10, 74S30

(C) Yadzhak, N., 2020 
generalize the equivalent area method which has been formulated earlier [1] p. 85-89] for the long cracks.

\section{Mathematical Model for Fatigue Growth of a Small Crack With a Convex Contour}

Consider a three-dimensional body with a plane small crack of an initial area $S_{0}$ subject to cyclic loading of an amplitude $p$ and a period of cycle $T$ (fig. 1). The external loading is applied in a way that the stress-strain state is symmetric about the crack plane. In this case, the stress-strain state in the fracture process zone in front of the crack tip can be described only by its opening $\delta_{I}[4$, p. 29-30].

The problem is to determine the number of load cycles $N=N_{*}$, when as result of fatigue fracture the crack rises to the critical size $S=S_{*}$ and the body collapses.

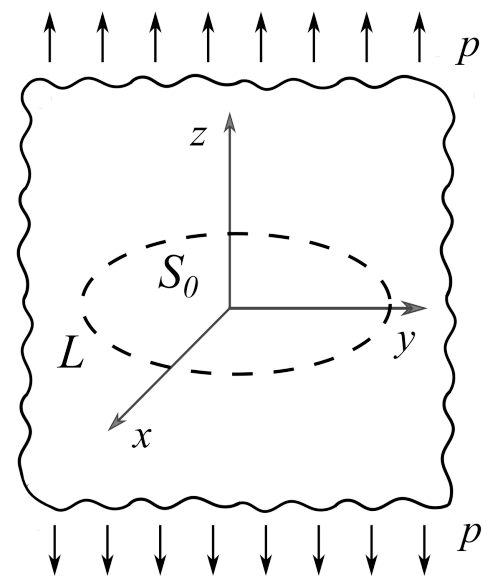

FIG. 1. Three-dimensional body with a small plane crack

Since the crack size is small and the self-similarity conditions are not met [4, p. 29], the energy approach in deformation parameters $[2$ is used to solve the problem.

Taking into account that under fatigue loading, the crack grows by small jumps of size $\Delta S_{c}$ over a large number of cycles $\Delta N_{c}$, the crack growth can be considered to be continuous from the initial size $S=S_{0}$ to the final one $S=S_{*}[5]$. Then the crack growth rate $V$ can be written as follows:

$$
V=\frac{d S}{d N} \approx \frac{\Delta S_{c}}{\Delta N_{c}} .
$$

For each crack jump $\Delta S_{c}$, the energy balance has the following form [2] 6]:

$$
A=W+\Gamma,
$$

where $A$ is the work of external forces, $W$ the deformation energy, and $\Gamma$ the fracture energy of a body for the crack area change. 
The deformation energy $W$ generated with the crack propagation on a jump size $\Delta S_{c}$, consists of the following components [5]:

$$
W=W_{s}+W_{p}^{(1)}(S)-W_{p}^{(2)}(t),
$$

where $W_{S}$ is the elastic component of $W ; W_{p}^{(1)}(S)$ is the part of the work of plastic deformations that depends only on the crack area $S ; W_{p}^{(2)}(t)$ is the part of the work of plastic deformations that depends only on time $t$ (respectively, the number of loading cycles $N=t T^{-1}$ ) and is generated by the body during its unloading and compression of the fracture process zone.

From the condition of the energy rate balance 2,6

$$
\frac{\partial A}{\partial N}=\frac{\partial W}{\partial N}+\frac{\partial \Gamma}{\partial N}
$$

and with respect to the energy balance (1), we obtain 6

$$
\frac{\partial}{\partial S}\left[\Gamma-\left(A-W_{s}-W_{p}^{(1)}\right)\right] \frac{d S}{d N}-\frac{\partial W_{p}^{(2)}}{\partial N}=0 .
$$

Then from equation $(2)$, the crack growth rate can be derived 6

$$
\frac{d S}{d N}=\left[\frac{\partial W_{p}^{(2)}}{\partial N}\right] / \frac{\partial}{\partial S}\left[\Gamma-\left(A-W_{s}-W_{p}^{(1)}\right)\right] .
$$

According to [2,5], the denominator in (3) can be rewritten in the form

$$
\frac{\partial}{\partial S}\left[\Gamma-\left(A-W_{s}-W_{p}^{(1)}\right)\right]=\gamma_{f}-L^{-1} \int_{L} \sigma_{t}(\xi) \delta_{t \max }(0, \xi) d \xi
$$

where $L$ is the crack contour; $\gamma_{f}$ the specific fracture energy at fatigue crack propagation that is determined by the formula $\gamma_{f}=\sigma_{t} \delta_{c} ; \sigma_{t}$ the average strain in the fracture process zone; $\delta_{t \max }(0, \xi)$ the maximal opening $\delta_{t}(0, \xi)$ of the fracture process zone near the crack contour per cycle for the stress $\sigma_{t} ; \delta_{c}$ the critical opening of the fracture process zone, and $\xi$ is the coordinate on the crack contour $L$.

To determine the work of plastic deformations $W_{p}^{(2)}(t)$ generated by the body during its unloading and compression of the fracture process zone, let us first calculate the length of the crack jump during its fatigue propagation [7, p. 133]:

$$
l_{f p} \approx \alpha_{0} \Delta \delta_{t}(0, \xi)=\alpha_{0}\left[\delta_{t \max }(0, \xi)-\delta_{t \min }(0, \xi)\right],
$$

where $\alpha_{0}$ is a constant determined from an experiment, and $\delta_{t \min }(0, \xi)$ is the minimal opening $\delta_{t}(0, \xi)$ of the fracture process zone per cycle.

Since the opening $\delta_{t}(x, \xi)$ changes little in a small neighbourhood of the crack contour and it is considered to be constant over the variable $x[7$,

$$
\delta_{t}(x, \xi) \approx \delta_{t}(0, \xi) \text { at } 0 \leq x \leq x_{*},
$$

the work of plastic deformations $W_{p}^{(2)}(t)$ can be expressed by the formula 8 :

$$
W_{p}^{(2)}(N)=\alpha_{0} N\left(\int_{L} \sigma_{t}\left[\delta_{t \max }(0, \xi)-\delta_{t \min }(0, \xi)\right]^{2} d \xi-W_{0}^{(2)}\right),
$$


where $W_{0}^{(2)}$ is the energy per cycle that does not initiate fatigue fracture of the material, defined as 8

$$
W_{0}^{(2)}=\int_{L} \sigma_{t}(\xi) N\left(\delta_{t h \max }-\delta_{t h \min }\right)^{2} d \xi,
$$

$\delta_{\text {thmax }}$ and $\delta_{\text {thmin }}$ is the maximal and the minimal values of the lower threshold of the opening of the fracture process zone near the crack contour $\delta_{t h}$ at which the crack does not propagate.

Then, the combination of (6), (4) and (3) gives the following formula for the fatigue crack growth rate 8 :

$$
\frac{d S}{d N}=\frac{\alpha_{0}\left(1-R_{\delta}\right)^{2} \int_{L} \sigma_{t}\left[\delta_{t \max }^{2}(0, \xi)-\delta_{t h \min }^{2}\right] d \xi}{\sigma_{t} \delta_{f c}-L^{-1} \int_{L} \sigma_{t}(\xi) \delta_{t \max }(0, \xi) d \xi},
$$

where $\delta_{f c}$ is the critical value of the fracture process zone $\delta_{t}$ under fatigue loading.

Initial and final conditions for this problem are the following:

$$
N=0, \quad S(0)=S_{0} ;
$$

and, respectively,

$$
N=N_{*}, \quad S\left(N_{*}\right)=S_{*} .
$$

The critical area value $S_{*}$, at which the fracture occurs, can be expressed from the critical crack opening displacement criterion [4, p. 139]:

$$
\delta_{t}\left(S_{*}\right)=\delta_{f c} .
$$

Hence, the mathematical model (7)-(10) allows calculating the period of subcritical growth of a small fatigue crack with a convex contour.

\section{Generalization of the Equivalent Area Method for Small Cracks}

The application of the mathematical model $(7)-(10)$ for determination of residual lifetime for cracks of arbitrary contours involves mathematical difficulties 2 . In order to simplify the solution process, let us generalize the equivalent area method for the case of short fatigue cracks.

Suppose that the energy values $W_{p}^{(1)}$ and $W_{p}^{(2)}$ slightly differ for two arbitrary small cracks of convex contours $L$ and equal area $S$ under the condition of homogenous tensile stresses $p$. In this regard, one of these configurations can be replaced by a circle of radius $r$ and equal length $S=\pi r^{2}$. According to the assumption, a crack of an arbitrary convex contour $L$ and an equal length has the energy values $W_{p}^{(1)}$ and $W_{p}^{(2)}$ that only slightly differ from the corresponding values for a circular crack $W_{p}^{(1)(c)}$ and $W_{p}^{(2)(c)} \sqrt{2}$.

Thus, the character of the area change for a crack with an arbitrary convex contour $L$ and a crack of a circular contour with the equal area $S$ are close. This concept is in agreement with the ideas described in [1, p. 85-89]. 
Let us use this approach to the problem in consideration. Based on the equivalent area method, let us substitute the small plane crack of a convex contour for a circular crack of the initial radius $r_{0}$ and the equal area [1, p. 85]:

$$
S_{0}=S_{0}^{(c)}
$$

where $S_{0}$ is the initial area of the plane crack, and $S_{0}^{(c)}=\pi r_{0}^{2}$ is the area of the equivalent circular crack.

From relation (11), the value of the initial radius of the equivalent short crack can be obtained [1, p. 87]:

$$
r_{0}=\sqrt{S_{0} / \pi}
$$

The growth rate of the circular crack based on (7) can be written in the following form as a function of the opening of its fracture process zone 8 :

$$
V=\alpha_{0}\left(1-R^{2}\right)^{2} \frac{\left(\delta_{I}^{(c)}\right)^{2}-\delta_{t h}^{2}}{\delta_{I c}-\delta_{I}^{(c)}}
$$

where $R$ is the load ratio, and $\delta_{I}^{(c)}$ is the opening of the fracture process zone of the circular crack.

Consequently, the solution of the problem, similarly to [3], can be reduced to the following mathematical model:

$$
\frac{d r}{d N}=\alpha_{0}\left(1-R^{2}\right)^{2} \frac{\left(\delta_{I}^{(c)}\right)^{2}-\delta_{t h}^{2}}{\delta_{I c}-\delta_{I}^{(c)}}
$$

with initial

and final conditions

$$
N=0, r(0)=r_{0}=\sqrt{S_{0} / \pi}
$$

$$
N=N_{*}, \quad r\left(N_{*}\right)=r_{*} .
$$

The critical value of the circular crack radius $r_{*}$ can be found using the critical crack opening displacement criterion (10):

$$
\delta_{I}^{(c)}\left(r_{*}\right)=\delta_{I c} .
$$

Thus, the problem is reduced to the determination of the opening of the fracture process zone for a circular crack.

\section{Evaluation of the Opening of the Fracture Process Zone in Front of the Contour of a Circular Crack}

Consider an infinite elastic body with an inner disc-shaped crack of radius $a$ (fig. 2 ) subject to tension at infinity by uniformly distributed loading of intensity $p$, directed orthogonally to the crack face [4, p. 199].

During the loading process, a plastic zone appears in the neighbourhood of the crack contour in the form of a plain ring of the size $R-a$, where $R$ is the boundary radius between the regions of elastic and plastic deformations 4 , p. 199]. 


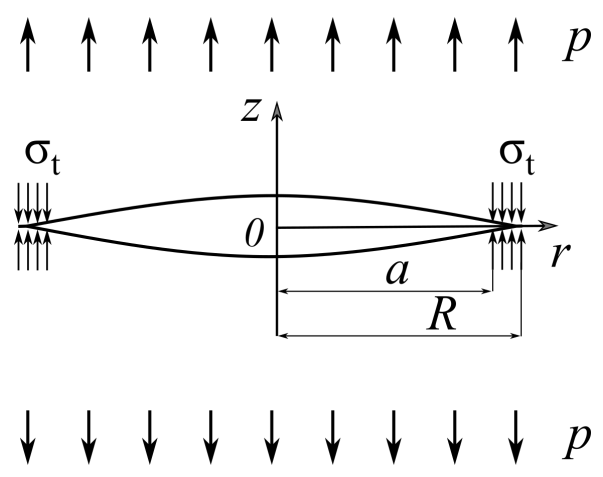

Fig. 2. Uniaxial tension of a tree-dimensional body with a disc-shaped crack [4, p. 199]

The opening of the fracture process zone $\delta_{I}$ for the generalized Sack's problem is given by the formula [4, p. 200]:

$$
\delta_{I}=\frac{8 a \sigma_{t}\left(1-\nu^{2}\right) \cdot\left(1-\sqrt{1-\left(\frac{p}{\sigma_{t}}\right)^{2}}\right)}{\pi E},
$$

where $\nu$ is Poisson's ratio, $\sigma_{t}$ the yield stress, and $E$ Young's modulus.

Based on formula (17), the following expression can be obtained via numerical analysis for determination of the opening of the fracture process zone:

$$
\delta_{I}=\frac{4 a p^{2}\left(1-\nu^{2}\right)}{\pi \sigma_{t} E \sqrt[4]{1-\left(\frac{p}{\sigma_{t}}\right)^{2}}}
$$

or in the SIF parameters

$$
\delta_{I}=\frac{K_{I}^{2}\left(1-\nu^{2}\right)}{\sigma_{t} E \sqrt[4]{1-\left(\frac{p}{\sigma_{t}}\right)^{2}}},
$$

where the stress intensity factor (SIF) $K_{I}$ for Sack's problem is given by $[9$ p. 131]:

$$
K_{I}=\frac{2 \sqrt{a} p}{\sqrt{\pi}} .
$$

A comparison of the openings of the fracture process zone obtained by the proposed formula (18) and (17), conducted for a specimen from steel $65 \Gamma$ (analogue to 1066) with the following properties: $E=2 \cdot 10^{5} \mathrm{MPa}, \sigma_{t}=910 \mathrm{MPa}$ [10, shows that the proposed formula models quite well the exact relation between the opening of the fracture process zone and the crack size for different load values for the generalized Sack's problem. 
To solve the generalised Sack's problem and determine the critical loading under uniaxial loading of a three-dimensional body, the following relation can be used [4 p. 202]:

$$
p_{*}=\left\{\begin{array}{l}
\sigma_{t}, \quad a<a_{*} ; \\
\sigma_{t} \sqrt{2 a_{*} / a} \sqrt{1-a_{*} / 2 a}, \quad a>a_{*} .
\end{array}\right.
$$

Relation 19 can be also employed to determine the critical loading of a threedimensional body. It is known [4, p. 201] that the critical crack size for the generalised Sack's problem is calculated by the formula:

$$
a_{*}=\frac{\pi E \delta_{I}}{8 \sigma_{t}\left(1-\nu^{2}\right)} .
$$

Then having substituted 22 into the obtained formula for determination of the opening of the fracture process zone in front of a crack contour 18 and having grouped the dimensionless loading values $p_{*} / \sigma_{t}$ and crack sizes $a / a_{*}$, we obtain the following expression for the critical loading:

$$
\frac{1}{16}\left(\frac{p_{*}}{\sigma_{t}}\right)^{8}\left(\frac{a}{a_{*}}\right)^{4}+\left(\frac{p_{*}}{\sigma_{t}}\right)^{2}=1
$$

Fig. 3 presents the comparison of the solutions obtained by formulas (21) and $(23)$. It is shown that formula (23) is correct for solving of the generalized Sack's problem and contrary to 21, models the relation between the stress and the crack size by one relation in the whole range of the dimensionless crack size. Thus, formula $(23)$ is valid both for spontaneous fracture $\left(a / a_{*}>1\right)$ and for subcritical crack growth $\left(a / a_{*}<1\right)$.

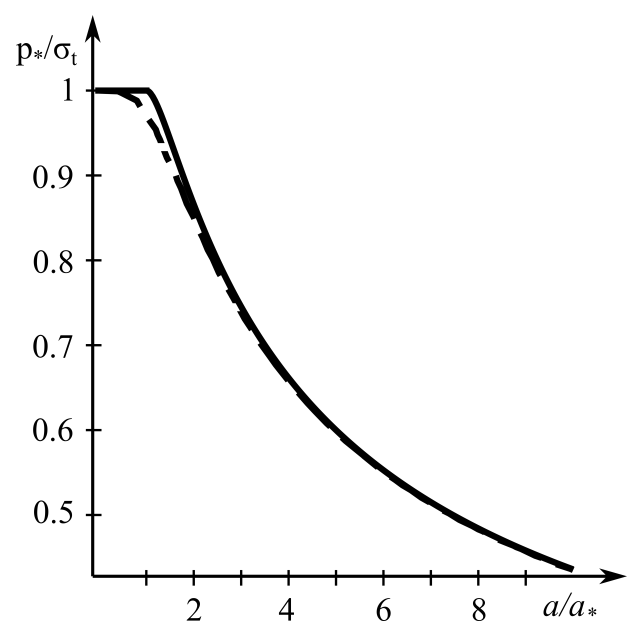

FIG. 3. Solution comparison of the generalized Sack's problem: solid line is the exact solution by the formula (21), dashed line solution by (23)

In addition, let us conduct a numerical experiment based on the generalized Sack's problem for the steel 65Г (analogue to 1066) using the proposed formula for determination 
of the opening of the fracture process zone (19). On Griffith's problem, it has been verified $[8,11,12$ that the approach to present the crack growth rate via the opening in its tip is invariant contrary to the employment of a stress intensity factor. Let us use this approach to Sack's problem for a three-dimensional body.

It is considered that the crack sizes are kept within the range $1 \leq a \leq 10 \mathrm{~mm}$. The material properties (steel $65 \Gamma$ (analogue to 1066) tempered at $600{ }^{\circ} \mathrm{C}$ ) $[10] R=0.1$, $E=2.1 \cdot 10^{5} \mathrm{MPa}, \sigma_{t}=910 \mathrm{MPa}, \nu=0.3, \Delta K_{t h}=7.4 \mathrm{MPa} \sqrt{\mathrm{m}}, \Delta K_{f c}=118 \mathrm{MPa} \sqrt{\mathrm{m}}$ are used to calculate the initial data and experimental parameters: $K_{t h}=8.2 \mathrm{MPa} \sqrt{\mathrm{m}}$, $K_{f c}=131.1 \mathrm{MPa} \sqrt{\mathrm{m}}, \delta_{c}=8.99 \cdot 10^{-5} \mathrm{~m}, \delta_{t h}=3.54 \cdot 10^{-7} \mathrm{~m}, \alpha_{0}=0.197$.

The experiment is conducted for five crack propagation series at different fatigue loading values $p: 1-500 \mathrm{MPa}, 2-700 \mathrm{MPa}, 3-800 \mathrm{MPa}, 4-850 \mathrm{MPa}, 5-875 \mathrm{MPa}$.

For each loading series, we find the stress intensity factor by formula $(20)$, the opening of the fracture process zone by formula 19 and the crack growth rate using (12).

Based on the obtained values, graphical relations are built between the crack growth rate and the SIF $V \sim K_{I}$ (fig. 44 as well as between the crack growth rate and the opening of the fracture process zone in front of the crack contour $V \sim \delta_{I}$ (fig. 5 ).

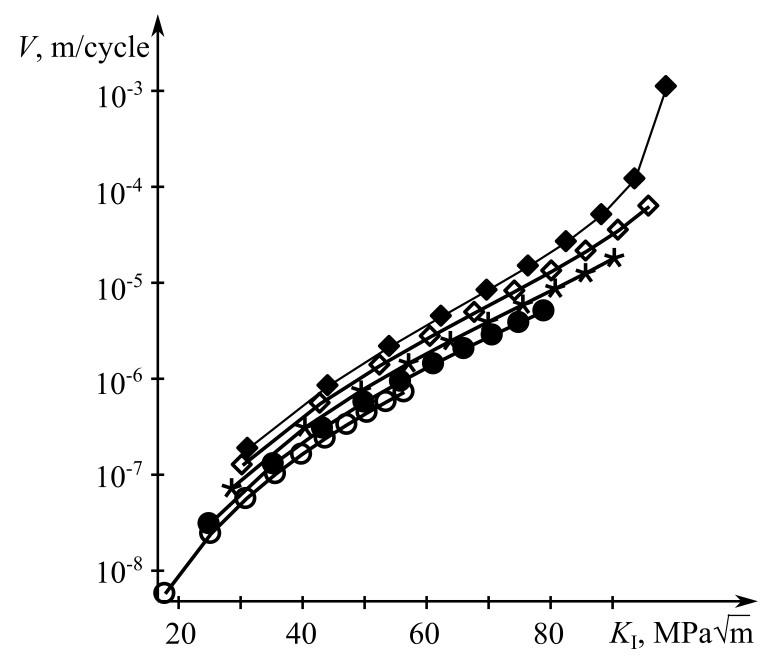

FIG. 4. Relation between the crack growth rate $V$ and the stress intensity factor $K_{I}$ at the series of loading $p: 1(\diamond)-875 \mathrm{MPa}, 2(\diamond)-850 \mathrm{MPa}$, $3(*)-800 \mathrm{MPa}, 4(\bullet)-700 \mathrm{MPa}, 5(\circ)-500 \mathrm{MPa}$

Fig. 4 shows that points obtained at different load levels are located on parallel curves. Thus, one value of SIF corresponds to several values of crack growth rate $V$ at different load levels $p$. This difference in the results emerges due to plasticity, since the plasticity zone formation for the case of small cracks is not considered in the SIFapproach contrary to the $\delta_{I}$-approach. Higher divergence level is observed for higher load 
levels due to the increase of the plasticity zone and expressed in formula $(19)$ by the factor $\sqrt[4]{1-\left(p / \sigma_{p}\right)^{2}}$.

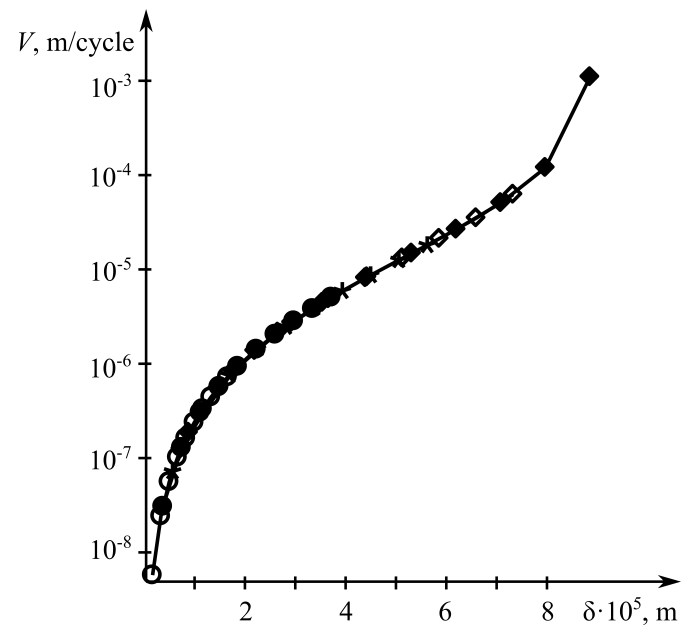

FIG. 5. Relation between the crack growth rate $V$ and the opening of the fracture process zone $\delta_{I}$ at the series of loading $p$ : $-875 \mathrm{MPa}$, $\diamond-850 \mathrm{MPa},{ }^{*}-800 \mathrm{MPa}, \bullet-700 \mathrm{MPa}, \circ-500 \mathrm{MPa}$

On the contrary to the fig. 4 one value of the opening of the fracture process zone $\delta_{I}$ corresponds to one value of the crack growth rate $V$, as all the values for different load levels are located on a single curve (fig. 55). This indicates the invariant character of the crack growth rate representation in the coordinates $V \sim \delta_{I}$ towards the load level.

Thus, for the three-dimensional problem, the obtained result is similar to the one for the plane problem: the representation of the crack growth rate via the opening of the fracture process zone $\delta_{I}$ is invariant on the contrary to the rate representation using the stress intensity factor $K_{I}$.

\section{Generalization of the Equivalent Area Method for Small Cracks (CONTINUATION)}

Let us return to the equivalent area method for short cracks. Considering that the opening of the fracture process zone in front of the crack contour $\delta_{I}^{(c)}$ can be calculated by formula (19) proposed above, a formula for determination of subcritical crack growth period $N_{*}$ is obtained from expression (13) taking into account the relations (19), 20) and the boundary conditions (14), 15):

$$
N_{*}=\frac{\pi E \sigma_{t} \sqrt[4]{1-\left(p / \sigma_{t}\right)^{2}}}{\alpha_{0}\left(1-R^{2}\right)^{2}} \int_{r_{0}}^{r_{*}} \frac{\delta_{I} \pi E \sigma_{t} \sqrt[4]{1-\left(p / \sigma_{t}\right)^{2}}-4 r p^{2}\left(1-\nu^{2}\right)}{16 r^{2} p^{4}\left(1-\nu^{2}\right)^{2}-\left(\delta_{t h} \pi E \sigma_{t} \sqrt[4]{1-\left(p / \sigma_{t}\right)^{2}}\right)^{2}} d r .
$$


After integration, the relation between the period of subcritical crack growth $N_{*}$ and crack radius $r$ can be represented as

$$
\begin{aligned}
N_{*}=\frac{\pi E \sigma_{t}}{8 \alpha_{0} p^{2}\left(1-\nu^{2}\right)\left(1-R^{2}\right)^{2}}\left[\frac{\delta_{I c}}{\delta_{t h}} \ln \mid \frac{4 r p^{2}\left(1-\nu^{2}\right)-\delta_{t h} \pi E \sigma_{t} \sqrt[4]{1-\left(p / \sigma_{t}\right)^{2}}}{4 r p^{2}\left(1-\nu^{2}\right)+\delta_{t h} \pi E \sigma_{t} \sqrt[4]{1-\left(p / \sigma_{t}\right)^{2}}}\right. \\
\times \frac{4 \sqrt{S_{0} / \pi} p^{2}\left(1-\nu^{2}\right)+\delta_{t h} \pi E \sigma_{t} \sqrt[4]{1-\left(p / \sigma_{t}\right)^{2}}}{4 \sqrt{S_{0} / \pi} p^{2}\left(1-\nu^{2}\right)-\delta_{t h} \pi E \sigma_{t} \sqrt[4]{1-\left(p / \sigma_{t}\right)^{2}}} \mid- \\
\left.-\ln \left|\frac{16 r^{2} p^{4}\left(1-\nu^{2}\right)^{2}-\left(\delta_{t h} \pi E \sigma_{t} \sqrt[4]{1-\left(p / \sigma_{t}\right)^{2}}\right)^{2}}{16 S_{0} / \pi p^{4}\left(1-\nu^{2}\right)^{2}-\left(\delta_{t h} \pi E \sigma_{t} \sqrt[4]{1-\left(p / \sigma_{t}\right)^{2}}\right)^{2}}\right|\right]
\end{aligned}
$$

The critical value of the crack radius $r_{*}$, obtained by the critical crack opening displacement criterion (16) using the formula for the opening of the fracture process zone (18),

$$
r_{*}=\frac{\delta_{I c} \pi E \sigma_{t} \sqrt[4]{1-\left(p / \sigma_{t}\right)^{2}}}{8 p^{2}\left(1-\nu^{2}\right)},
$$

corresponds to the following lifetime of the body:

$$
\begin{gathered}
N_{*}=\frac{\pi E \sigma_{t} \sqrt[4]{1-\left(p / \sigma_{t}\right)^{2}}}{8 \alpha_{0} p^{2}\left(1-\nu^{2}\right)\left(1-R^{2}\right)^{2}} \\
\times\left[\frac{\delta_{I c}}{\delta_{t h}} \ln \left|\frac{\delta_{I c}-\delta_{t h}}{\delta_{I c}+\delta_{t h}} \cdot \frac{4 \sqrt{S_{0} / \pi} p^{2}\left(1-\nu^{2}\right)+\delta_{t h} \pi E \sigma_{t} \sqrt[4]{1-\left(p / \sigma_{t}\right)^{2}}}{4 \sqrt{S_{0} / \pi} p^{2}\left(1-\nu^{2}\right)-\delta_{t h} \pi E \sigma_{t} \sqrt[4]{1-\left(p / \sigma_{t}\right)^{2}}}\right|\right. \\
\left.-\ln \left|\frac{\left(\delta_{I c}^{2}-\delta_{t h}^{2}\right)\left(\pi E \sigma_{t} \sqrt[4]{1-\left(p / \sigma_{t}\right)^{2}}\right)^{2}}{16 S_{0} / \pi p^{4}\left(1-\nu^{2}\right)^{2}-\left(\delta_{t h} \pi E \sigma_{t} \sqrt[4]{1-\left(p / \sigma_{t}\right)^{2}}\right)^{2}}\right|\right]
\end{gathered}
$$

Thus, formulas 25 and $(27)$ give the solution for the problem of cyclical tension of a three-dimensional body with a small crack of an arbitrary convex contour using the equivalent area method through the radius of an equivalent circle crack.

\section{Solution of the Problem of Cyclical Tension of a Body with a \\ Small Elliptical Crack Contour Using the Equivalent Area MethoD}

In order to verify the accuracy of the proposed approach for the approximate lifetime evaluation of structural elements using the equivalent area method, let us consider a specific example: a uniform three-dimensional body with an inner small elliptical crack 
with semiaxes $a_{0}$ and $b_{0}$ (fig. 6). The body is subject to uniformly distributed cyclic tension $p$ applied at the infinity. The problem is to determine a period of subcritical growth $N=N_{*}$ when the crack grows to the critical values $a_{*}, b_{*}$ and the body collapses.

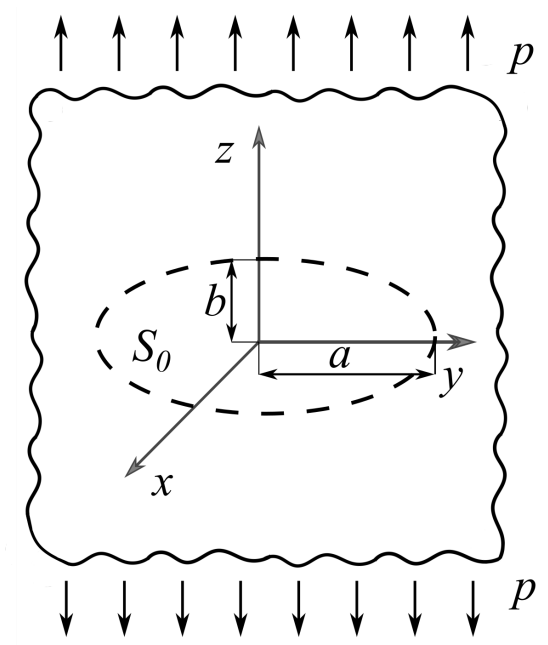

FIG. 6. Three-dimensional body with an elliptical crack 3

Introduce a cartesian coordinate system Oxyz so that the crack is located on the plane $z=0$, axis $x$ coincides with the major semiaxis of the ellipse $2 a$ and axis $y$ with the minor semiaxis $2 b$.

The solution of the problem is sought by two methods: the generalized equivalent area method and the numerical Runge-Kutta method, and the obtained results are compared.

Based on the equivalent area method [1, p. 85-89], the elliptical crack with semiaxes $a_{0}$ and $b_{0}$ is substituted by a circular crack of an equal area and initial radius $r_{0}$ :

$$
S_{0}^{(e)}=S_{0}^{(c)},
$$

where $S_{0}^{(e)}=\pi a_{0} b_{0}$ is the initial area of the elliptical crack, and $S_{0}^{(c)}=\pi r_{0}^{2}$ is the initial area of an equivalent circular crack (fig. 7).

From relation (28), the value of the initial radius of an equivalent circular crack can be obtained:

$$
r_{0}=\sqrt{a_{0} b_{0}} .
$$

Similarly to the previous case, the solution of the problem is reduced to the mathematical model (13)- 15$)$ taking into account the initial condition $(29)$.

Then from relation (24) after integration in the range of (29) and (26), a formula for determination of the period of subcritical crack growth $N_{*}$ depending on the radius $r$ can be derived: 


$$
\begin{gathered}
N_{*}=\frac{\pi E \sigma_{t} \sqrt[4]{1-\left(p / \sigma_{t}\right)^{2}}}{8 \alpha_{0} p^{2}\left(1-\nu^{2}\right)\left(1-R^{2}\right)^{2}}\left[\frac{\delta_{I c}}{\delta_{t h}} \ln \mid \frac{4 r p^{2}\left(1-\nu^{2}\right)-\delta_{t h} \pi E \sigma_{t} \sqrt[4]{1-\left(p / \sigma_{t}\right)^{2}}}{4 r p^{2}\left(1-\nu^{2}\right)+\delta_{t h} \pi E \sigma_{t} \sqrt[4]{1-\left(p / \sigma_{t}\right)^{2}}}\right. \\
\times \frac{4 \sqrt{a_{0} b_{0}} p^{2}\left(1-\nu^{2}\right)+\delta_{t h} \pi E \sigma_{t} \sqrt[4]{1-\left(p / \sigma_{t}\right)^{2}}}{4 \sqrt{a_{0} b_{0}} p^{2}\left(1-\nu^{2}\right)-\delta_{t h} \pi E \sigma_{t} \sqrt[4]{1-\left(p / \sigma_{t}\right)^{2}}} \mid \\
\left.-\ln \left|\frac{16 r^{2} p^{4}\left(1-\nu^{2}\right)^{2}-\left(\delta_{t h} \pi E \sigma_{t} \sqrt[4]{1-\left(p / \sigma_{t}\right)^{2}}\right)^{2}}{16 a_{0} b_{0} p^{4}\left(1-\nu^{2}\right)^{2}-\left(\delta_{t h} \pi E \sigma_{t} \sqrt[4]{1-\left(p / \sigma_{t}\right)^{2}}\right)^{2}}\right|\right]
\end{gathered}
$$

The critical value of the crack radius $r_{*}$, found in $(30)$, corresponds to the following lifetime of the body:

$$
\begin{gathered}
N_{*}=\frac{\pi E \sigma_{t} \sqrt[4]{1-\left(p / \sigma_{t}\right)^{2}}}{8 \alpha_{0} p^{2}\left(1-\nu^{2}\right)\left(1-R^{2}\right)^{2}} \\
\times\left[\frac{\delta_{I c}}{\delta_{t h}} \ln \left|\frac{\delta_{I c}-\delta_{t h}}{\delta_{I c}+\delta_{t h}} \cdot \frac{4 \sqrt{a_{0} b_{0}} p^{2}\left(1-\nu^{2}\right)+\delta_{t h} \pi E \sigma_{t} \sqrt[4]{1-\left(p / \sigma_{t}\right)^{2}}}{4 \sqrt{a_{0} b_{0}} p^{2}\left(1-\nu^{2}\right)-\delta_{t h} \pi E \sigma_{t} \sqrt[4]{1-\left(p / \sigma_{t}\right)^{2}}}\right|\right. \\
\left.-\ln \left|\frac{\left(\delta_{I c}^{2}-\delta_{t h}^{2}\right)\left(\pi E \sigma_{t} \sqrt[4]{1-\left(p / \sigma_{t}\right)^{2}}\right)^{2}}{16 a_{0} b_{0} p^{4}\left(1-\nu^{2}\right)^{2}-\left(\delta_{t h} \pi E \sigma_{t} \sqrt[4]{1-\left(p / \sigma_{t}\right)^{2}}\right)^{2}}\right|\right] .
\end{gathered}
$$

Hence, formulas (30) and (31) represent the solution of the problem of cyclic tension of a three-dimensional body with an elliptical crack using the equivalent area method as a function of a radius of an equivalent circular crack.

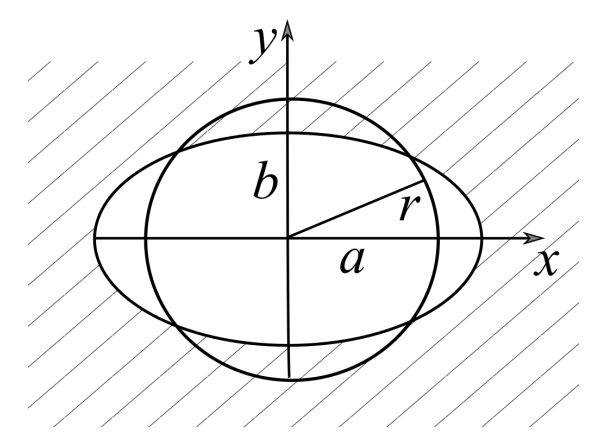

FIG. 7. Elliptical and equivalent circular crack [1, p. 86] 


\section{Lifetime Calculation of a Body with an Elliptical Crack by the Runge-Kutta Method}

Finally, let us find an exact solution of the problem of cyclic tension of a threedimensional body with an elliptical crack.

It is known [1, p. 85], [3 that for long cracks, the form of an elliptical crack only slightly differs from the elliptical in the process of its constant motion. Hence, the propagation of such crack can be modelled through the motion in the direction of its two semiaxes.

Under assumption that a small fatigue crack in the process of its growth also remains elliptical, the equation of motion for this crack dS/dN, that characterises the area change with change of the number of the loading cycles, can be reduced to two equations: equations that describe the change of the major and minor semiaxes of the ellipse.

In this case to solve the problem, the kinetics of crack motion in both semiaxes has to be known. Thus, analogically to (13), we obtain:

$$
\left\{\begin{array}{l}
\frac{d a}{d N}=f\left(\delta_{I a}^{(e)}\right) \\
\frac{d b}{d N}=f\left(\delta_{I b}^{(e)}\right)
\end{array}\right.
$$

where $f\left(\delta_{I a}^{(e)}\right)$ and $f\left(\delta_{I b}^{(e)}\right)$ are the functions that describe the growth rate of an elliptical crack through the opening of the fracture process zone in front of its contour $\delta_{I a}^{(e)}$ and $\delta_{I b}^{(e)}$ in the direction of the major $a$ and minor $b$ semiaxes of the ellipse.

The functions $f\left(\delta_{I a}^{(e)}\right)$ and $f\left(\delta_{I b}^{(e)}\right)$, build analogically to 12 , have the form:

$$
\begin{aligned}
& f\left(\delta_{I a}^{(e)}\right)=\alpha_{0}\left(1-R^{2}\right)^{2} \frac{\left(\delta_{I a}^{(e)}\right)^{2}-\delta_{t h}^{2}}{\delta_{I c}-\delta_{I a}^{(e)}} \\
& f\left(\delta_{I b}^{(e)}\right)=\alpha_{0}\left(1-R^{2}\right)^{2} \frac{\left(\delta_{I b}^{(e)}\right)^{2}-\delta_{t h}^{2}}{\delta_{I c}-\delta_{I b}^{(e)}}
\end{aligned}
$$

where according to 19 , the openings of the fracture process zone are given by:

$$
\delta_{I a}^{(e)}=\frac{\left(K_{I a}^{(e)}\right)^{2}\left(1-\nu^{2}\right)}{\sigma_{t} E \sqrt[4]{1-\left(\frac{p}{\sigma_{t}}\right)^{2}}} ; \quad \delta_{I b}^{(e)}=\frac{\left(K_{I b}^{(e)}\right)^{2}\left(1-\nu^{2}\right)}{\sigma_{t} E \sqrt[4]{1-\left(\frac{p}{\sigma_{t}}\right)^{2}}} .
$$

It is known, that the stress intensity factor for an inner elliptical crack changes along its contour in the following way [1, p. 99], [11, p. 88]:

$$
K_{I}=p \frac{\sqrt{\pi b}}{E(k)} \sqrt[4]{\sin ^{2} \beta+\frac{b^{2}}{a^{2}} \cos ^{2} \beta}
$$


where $\beta$ is the angular parameter, $k^{2}=1-\frac{b^{2}}{a^{2}}$, and $E(k)$ is the elliptic integral of second order:

$$
E(k)=\int_{0}^{\frac{\pi}{2}} \sqrt{1-k^{2} \sin ^{2} \theta} d \theta .
$$

The coordinates of an arbitrary point on the crack contour are given by the angular parameter $\beta$ and the semiaxes by the relations [1, p. 88]:

$$
x=a \cos \beta, y=b \sin \beta .
$$

Then based on (37) and (35), the SIF has the following forms for the major semiaxis of the ellipse at $x=a$ :

$$
K_{I a}^{(e)}=\frac{p b \sqrt{\pi}}{\sqrt{a} E(k)},
$$

and for the minor semiaxis at $y=b$, respectively

$$
K_{I b}^{(e)}=\frac{p \sqrt{\pi b}}{E(k)} .
$$

Taking into consideration functions (33), the opening of the fracture process zone 34 and the SIFs (38), (39), we obtain from system (32):

$$
\left\{\begin{array}{l}
\frac{d a}{d N}=\frac{\alpha_{0}\left(1-R^{2}\right)^{2}}{a(E(k))^{2} E \sigma_{t} \sqrt[4]{1-\left(p / \sigma_{t}\right)^{2}}} \cdot \frac{\left(\pi b^{2} p^{2}\left(1-\nu^{2}\right)\right)^{2}-\left(a(E(k))^{2} \delta_{t h} E \sigma_{t} \sqrt[4]{1-\left(p / \sigma_{t}\right)^{2}}\right)^{2}}{a(E(k))^{2} \delta_{I c} E \sigma_{t} \sqrt[4]{1-\left(p / \sigma_{t}\right)^{2}}-\pi b^{2} p^{2}\left(1-\nu^{2}\right)} \\
\frac{d b}{d N}=\frac{\alpha_{0}\left(1-R^{2}\right)^{2}}{(E(k))^{2} E \sigma_{t} \sqrt[4]{1-\left(p / \sigma_{t}\right)^{2}}} \cdot \frac{\left(\pi b p^{2}\left(1-\nu^{2}\right)\right)^{2}-\left((E(k))^{2} \delta_{t h} E \sigma_{t} \sqrt[4]{1-\left(p / \sigma_{t}\right)^{2}}\right)^{2}}{(E(k))^{2} \delta_{I c} E \sigma_{t} \sqrt[4]{1-\left(p / \sigma_{t}\right)^{2}}-\pi b p^{2}\left(1-\nu^{2}\right)}
\end{array}\right.
$$

For the sake of simplicity, the integral $E(k)$, introduced by formula (36), can be expanded to series by the parameter $k[3]$ :

$$
E(k)=\frac{\pi}{2}\left[1-\sum_{n=1}^{\infty}\left(\frac{(2 n-1) ! !}{2^{n} n !}\right)^{2} \frac{k^{2 n}}{2 n-1}\right] .
$$

The solution of obtained system 40 with consideration of initial conditions:

$$
N=0, \quad a(0)=a_{0}, \quad b(0)=b_{0}
$$

is sought numerically by the Runge-Kutta method.

The calculation is performed for steel $65 \Gamma$ (analogue to 1066) with the following properties [10]: $\alpha_{0}=0.197, \nu=0.3, E=2.1 \cdot 10^{5} \mathrm{MPa}, \sigma_{t}=910 \mathrm{MPa}, \Delta K_{t h}=$ $7.4 \mathrm{MPa} \sqrt{\mathrm{m}} ; \Delta K_{f c}=118 \mathrm{MPa} \sqrt{\mathrm{m}}$, load ratio $R=0.1$, having applied loading $p=$ $900 \mathrm{MPa}$ to a cracked body with the initial crack sizes $a_{0}=1 \mathrm{~mm}, b_{0}=0.5 \mathrm{~mm}$.

According to the critical crack opening displacement criterion (10),

$$
\delta_{I a}^{(e)}\left(a_{*}, b_{*}\right)=\delta_{I c}, \quad \delta_{I b}^{(e)}\left(a_{*}, b_{*}\right)=\delta_{I c},
$$


critical sizes of the elliptical crack for the considered problem are $a_{*}=7 \mathrm{~mm}, b_{*}=7 \mathrm{~mm}$. The corresponding critical size of the equivalent circular crack due to $(26)$ is also $r_{*}=7 \mathrm{~mm}$.

As can be seen from the fig. 8 , the curves that describe the relation of subcritical growth period of an elliptical crack $N_{*}$ on its area $S_{*}$, obtained using the approximate generalised equivalent area method and the exact numerical Runge-Kutta method, are quite close. This indicates high accuracy of the generalized equivalent area method.

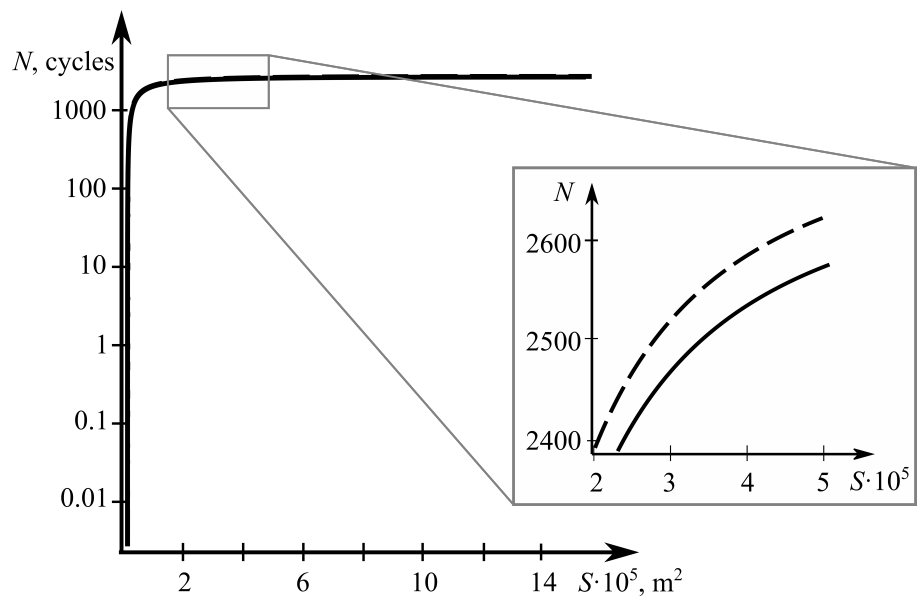

FIG. 8. Relation of subcritical growth period of an elliptical crack $N_{*}$ on its area $S_{*}$ : dashed line is obtained by the generalised equivalent area method, solid line by the Runge-Kutta method

Hence, the generalized equivalent area method can be applied to solve a problem of fatigue tension of a three-dimensional body with an elliptical crack that significantly simplifies the solution process compared to the exact method as well as enables to obtain an analytical relation $N_{*} \sim S_{*}$.

\section{Conclusions}

This study proposes a generalization of the equivalent area method, that is widely used to solve the problems with long cracks, for a case of short cracks. Firstly, a formula has been obtained to express the crack growth rate as a function of opening of the fracture process zone in front of the crack contour, and the invariancy of this approach has been shown for a three-dimensional cracked body. Secondly, the equivalent area method has been generalized for a case of short cracks. Based on the problem of fatigue tension of a three-dimensional body with an elliptical crack, it has been shown that the solution by the generalized equal area method with employment of the proposed relation between the crack growth rate and the opening of the fracture process zone differs little from the exact solution obtained numerically by the Runge-Kutta method. 


\section{ACKNowledgements}

I would like to thank Prof. Andreykiv for his valuable commentary and guidance.

\section{REFERENCES}

1. O. E. Andreykiv and A. I. Darchyk, Fatigue fracture and lifetime of constructions, Naukova Dumka, Kyiv, 1992, 184 p. (Russian).

2. M. Shata and Z. O. Terletska, An energy approach in mechanics of fatigue macrocrack propagation, Fracture Mechanics of Materials and Structural Integrity, 2 (1999), 141-148 (Ukrainian).

3. O. Andreikiv and N. Sas, Subcritical growth of a plane crack in a three-dimensional body under the conditions of high-temperature creep, Materials Science 44 (2008), no. 2, 163-174.

4. V. V. Panasyuk, Mechanics of quasibrittle fracture of materials, Naukova Dumka, Kyiv, 1991, 416 p. (Russian).

5. O. E. Andreykiv and N. B. Sas, Mathematical model for determination of the period of subcritical crack propagation under high temperature creep in solid bodies, Reports of the National Academy of Sciences of Ukraine 5 (2006), 47-52 (Ukrainian).

6. O. E. Andreikiv and N. B. Sas, Fracture mechanics of metallic plates under the conditions of high-temperature creep, Materials Science 42 (2006), no. 2, 210-219.

7. O. E. Andreykiv, V. R. Skalskyi, and I. Ya. Dolinska, Slow fracture of materials under local creep, Publishing center of the National Ivan Franko University of Lviv, Lviv, 2017, 399 p. (Ukrainian).

8. O. Andreykiv, N. Shtayura, and R. Yarema, Energy-based approach to evaluation of short fatigue crack growth rate in plates, Strength of Materials 49 (2017), no. 6, 778-787.

9. V. V. Panasyuk, O. E. Andreykiv, and V. Z. Parton, Fracture mechanics and strengh of materials, vol. 1, Naukova Dumka, Kyiv, 1988, 488 p. (Russian).

10. O. P. Datsyshyn, T. M. Lenkovskyi, and A. Y. Glazov, Specimen for the determination of fatigue thresholds under cyclic transverse shear, Materials Science 55 (2020), no. 4, 492-501.

11.O. E. Andreikiv, A. R. Lysyk, N. S. Shtayura, and A. V. Babii, Evaluation of the residual service life of thin-walled structural elements with short corrosion-fatigue cracks, Materials Science 53 (2018), no. 4, 514-521.

12. O. E. Andreikiv and N. S. Shtayura, Computational models of fatigue cracks growth in metallic materials under the action of force and physicochemical factors, Materials Science 54 (2019), no. 4, 465-476.

Стаття: надійшла до редколегї 25.11.2020

доопращъована 11.12.2020

прийнята до друку 23.12.2020 


\title{
УЗАГАЛЬНЕННЯ МЕТОДУ ЕКВІВАЛЕНТНИХ ПЛОЩ НА ВИПАДОК МАЛИХ ВТОМНИХ ТРІЩИН У ТРИВИМІРНИХ ТІЛАX
}

\author{
Наталія ЯДЖАК \\ Лъвівсъкий націоналъний університет імені Івана Франка, \\ вул. Університетсъка, 1, 79000, Львів \\ e-mail: nataliya.yadzhak@lnu.edu.ua
}

В інженерній практиці широко експлуатуються елементи конструкцій 3 малими тріщинами, проте відносно прості методи оцінки довговічності таких конструктивних елементів розроблено недостатньо. Запропоновано узагальнення методу еквівалентних площ на випадок малих втомних тріщин із використанням альтернативного представлення залежності швидкості росту тріщини від розкриття зони передруйнування біля контуру тріщини. Розв'язано задачу втомного розтягу тривимірного тіла з еліптичною тріщиною під впливом втомних навантажень аналітично за допомогою методу еквівалентних площ і чисельно методом Рунге-Кутта. Порівняння отриманих розв'язків доведено добру збіжність результатів, що підтверджує можливість використання узагальненого методу еквівалентних площ для розв'язання задач з малими тріщинами.

Ключові слова: малі тріщини, втомне руйнування тривимірних тіл, еліптична тріщина, метод еквівалентних площ, розкриття зони передруйнування. 